\title{
Synthesis and properties of CaAl-layered double hydroxides of hydrocalumite-type
}

\author{
${ }^{a}$ Viktor Tóth, ${ }^{b}$ Mónika Sipiczki, ${ }^{\mathrm{b}}$ Attila Pallagi, ${ }^{\mathrm{c}, \mathrm{d}}$ Ákos Kukovecz, \\ d,eZoltán Kónya, ' ${ }^{\mathrm{P}}$ ál Sipos, ${ }^{\mathrm{a}}$ István Pálinkó*
}

\author{
${ }^{a}$ Department of Organic Chemistry, University of Szeged, Dóm tér 8, H-6720 Szeged, Hungary \\ ${ }^{\mathrm{b}}$ Department of Inorganic and Analytical Chemistry, University of Szeged, Dóm tér 7, H-6270 Szeged, Hungary \\ “MTA-SZTE "Lendület" Porous Nanocomposites Research Group, Szeged, Rerrich B. tér 1, H-6720 Szeged, Hungary \\ ${ }^{\mathrm{d}}$ Department of Applied and Environmental Chemistry, University of Szeged, Rerrich B. tér 1, H-6720 Szeged, Hungary \\ e MTA-SZTE Reaction Kinetics and Surface Chemistry Research Group, Rerrich B. tér 1, H-6720 Szeged, Hungary
}

Received 2 July 2013; Revised 22 August 2013; Accepted 27 August 2013

\begin{abstract}
CaAl-layered double hydroxides (CaAl-LDHs) with various carbonate ion contents are essentially formed in Bayer liquors during the causticisation step in alumina production. Under well-defined conditions hemicarbonate is formed, which is beneficial in the process of retrieving both $\mathrm{Al}(\mathrm{OH})_{4}^{-}$ and $\mathrm{OH}^{-}$ions. In the current work, $\mathrm{Ca}_{2} \mathrm{Al}-\mathrm{LDH}$ s with various carbonate contents were prepared by the co-precipitation procedure and the products were dried in different ways. Structural information was obtained by a variety of methods, such as X-ray diffractometry (XRD), scanning electron microscopy (SEM) and energy-dispersive X-ray spectroscopy (EDX). Elemental maps were constructed through a combination of SEM images and EDX measurements. The targeted CaAl-hydrocalumites were successfully synthesised. It was found that the method used for drying did not influence the basal spacing although it significantly altered the particle sizes.
\end{abstract}

(c) 2013 Institute of Chemistry, Slovak Academy of Sciences

Keywords: CaAl-LDH, synthesis, drying methods, structural characterisation

\section{Introduction}

Layered double hydroxides (LDHs) are synthetic or natural lamellar hydroxides, generally with two kinds of metallic cations in the main layers and interlayer domains containing anionic species. They are represented by the general formula $\left[\mathrm{M}_{1-x}^{2+} \mathrm{M}_{x}^{3+}(\mathrm{OH})_{2}\right]^{x+}$ $\mathrm{A}_{x / m}^{m-} \cdot n \mathrm{H}_{2} \mathrm{O}$, where $\mathrm{M}^{2+}$ is a divalent cation, $\mathrm{M}^{3+}$ is a trivalent cation and $\mathrm{A}$ an interlamellar anion with charge $m^{-}$. LDHs consist of layers of metal cations $\left(\mathrm{M}^{2+}\right.$ and $\left.\mathrm{M}^{3+}\right)$, which are randomly distributed in the octahedral positions forming brucite-like structures (Palmer et al., 2009).
Hydrotalcite, the most prominent representative of LDHs, is produced when $\mathrm{M}^{2+}=\mathrm{Mg}^{2+}$ and $\mathrm{M}^{3+}=$ $\mathrm{Al}^{3+}$, affording the general formula of $\mathrm{Mg}_{6} \mathrm{Al}_{2}(\mathrm{OH})_{16}$ $\mathrm{CO}_{3} \cdot 4 \mathrm{H}_{2} \mathrm{O}$. Hydrocalumite is formed with $\mathrm{Ca}^{2+}$ and $\mathrm{Al}^{3+}$ cations and can be described by a general formula of $\left[\mathrm{Ca}_{2} \mathrm{Al}(\mathrm{OH})_{6}\right] \mathrm{A} \cdot n \mathrm{H}_{2} \mathrm{O}$. The structure of hydrocalumite and hydrocalumite-like materials is based on corrugated brucite-like main layers with an ordered arrangement of $\mathrm{Ca}^{2+}$ and $\mathrm{Al}^{3+}$ ions, seven- and six-coordinated, respectively, in a fixed ratio of $2: 1$ (Rousselot et al., 2002).

Co-precipitation is the method most frequently used in the preparation of hydrocalumite and hydro-

\footnotetext{
*Corresponding author, e-mail: palinko@chem.u-szeged.hu

$\ddagger$ Presented at the XXIVth International Conference on Coordination and Bioinorganic Chemistry, Smolenice, Slovakia, 2-7 June 2013.
} 
calumite-type materials (Messersmith \& Stupp, 1992; Williams \& Perrotta, 1998); this is based on the slow addition of a mixed solution of di- and trivalent metal salts to an alkaline solution.

One of the most important aspects of the LDHs is the anion intercalation. Some anions are preferentially intercalated to the interlayer space of the $\mathrm{LDH}$ over others, hence it may be used for targeted anion removal (Perrotta \& Williams, 1995; Perrotta et al., 1997; Hobbs et al., 2003; Zhang \& Reardon, 2005; Chrysochoou \& Dermatas, 2006; Zümreoglu-Karan \& Ay, 2012). From this perspective, the carbonate has a specific role, since this is the most preferably intercalated anion. The unwanted presence of the carbonate in the interlayer region significantly affects the usefulness (i.e., chemical reactivity) of the LDH. It can block the targeted anion removal via retarding or blocking the intercalation, making the presence of the carbonate ion a problem in industrial applications. The carbonate ion enters the interlamellar space during the separation of the LDH (e.g., filtration, drying); consequently, the effect of the drying has an important role as regards to further applications.

\section{Experimental}

Concentrated $\mathrm{NaOH}(\approx 20 \mathrm{M})$ stock solutions were prepared by dissolving a. r. grade solid $\mathrm{NaOH}$ (VWR, Hungary) in water (Millipore MilliQ, Hungary). Their carbonate content was minimised as previously described (Sipos et al., 2000).

The $\mathrm{CaCl}_{2}$ solutions were prepared from solid and anhydrous $\mathrm{CaCl}_{2}$ (98.1 mass \%; Molar Chemicals, Hungary), and the $\mathrm{NaAl}(\mathrm{OH})_{4}$ stock solution was prepared following the procedure published previously (Sipos et al., 1998). The $99.99 \%$ aluminium wire $(50.964 \mathrm{~g})$ was slowly added to the thermostated carbonate-free $\mathrm{NaOH}$ solution $\left(500 \mathrm{~cm}^{3} ; 8.0 \mathrm{M}\right)$ and the mixture was stirred continuously with a magnetic stirrer under an Allihn condenser equipped with a soda lime-containing drying tube. Under these conditions, dissolution of the aluminium wire required 5-6 days. The mass loss was found to be 7-8 g, including $6.0 \mathrm{~g}$ of $\mathrm{H}_{2}$ formation. The $\mathrm{NaAl}(\mathrm{OH})_{4}$ solution thus prepared was filtered on a polysulphone Nalgene filter, and the precise density of the Na-aluminate $\left(1.4045 \mathrm{~g} \mathrm{~cm}^{-3} ; 4.1219 \mathrm{M}\right)$ solution was determined on $\mathrm{a} \approx 10 \mathrm{~cm}^{3}$ volume pycnometer at $(25.0 \pm 0.1)^{\circ} \mathrm{C}$. All caustic solutions were stored in an airtight, causticresistant Pyrex bottle.

The carbonate-containing sample solutions were prepared by dissolving solid $\mathrm{Na}_{2} \mathrm{CO}_{3}$ (alt. grade Reanal, Hungary) in the $\mathrm{Al}(\mathrm{OH})_{4}^{-}$-containing alkaline solutions.

The precipitates thus formed were rapidly filtered until air-dry in a virtually $\mathrm{CO}_{2}$-free atmosphere with the aid of a caustic-resistant vacuum filter unit (Nalgene) equipped with an appropriate membrane (Ver- sapor, $0.45 \mu \mathrm{m}$ ) and the solid material was washed using small quantities of water.

The formation of the LDHs was primarily examined using the powder X-ray diffraction (XRD) patterns of the solid samples measured on a Philips PW1710 instrument, using $\mathrm{Cu} K_{\alpha}(\lambda=1.5418 \AA)$ radiation (Philips, The Netherlands). The samples were pasted (generally $150 \mathrm{mg}$ ) onto the quartz sampleholder. Diffraction peak positions were determined by fitting a Gaussian function. Peak positions were found to be reproducible within $0.05^{\circ} 2 \theta$ values, hence the uncertainty of the basal spacing was estimated as $\pm 0.01 \mathrm{~nm}$.

The morphologies of the substances thus obtained were studied using a Hitachi S-4700 (Japan) scanning electron microscope (SEM) over a range of magnifications $(1,000-90,000)$. Acceleration voltage was set at $10 \mathrm{kV}$. The samples were ground prior to fixing them on a double-sided adhesive carbon tape. They were coated with a few nanometers thick gold layer, in order to obtain images with greater contrast, using a sputter coater (Quorum Technologies SC7620, USA).

The relative quantities of the ions in the solid samples were determined using a Röntec QX2 (Germany) energy-dispersive X-ray (EDX) spectrometer coupled to the microscope.

\section{Results and discussion}

The CaAl-LDHs were prepared using the coprecipitation method in two different ways. In the first case, $100 \mathrm{~cm}^{3}$ of a solution containing both metal ions (0.30 $\mathrm{M} \mathrm{CaCl}_{2}$ and $0.15 \mathrm{M} \mathrm{AlCl}_{3}$ ) was added dropwise to $40 \mathrm{~cm}^{3}$ of $3.0 \mathrm{M} \mathrm{NaOH}$ solution. During the preparation, the temperature was set at $(60 \pm 1)^{\circ} \mathrm{C}$. The second case involved a modified co-precipitation method, i.e. instead of the dropwise addition of the mixed metal salts to the $\mathrm{OH}^{-}$solution, the $\mathrm{Ca}^{2+}$ solution was added slowly to the alkaline solution containing aluminium. $100 \mathrm{~cm}^{3}$ of $0.30 \mathrm{M} \mathrm{CaCl}_{2}$ solution was added dropwise to a solution containing $\mathrm{NaOH}$ and $\mathrm{Al}(\mathrm{OH})_{4}^{-}$at $(60 \pm 1)^{\circ} \mathrm{C}$. The total concentrations of the $\mathrm{NaOH}$ and $\mathrm{Al}(\mathrm{OH})_{4}^{-}$in the starting solution of $38.65 \mathrm{~cm}^{3}$ were $3.1 \mathrm{M}$ and $0.39 \mathrm{M}$, respectively. The white precipitates were stirred continuously overnight prior to filtration. The $\mathrm{CO}_{3}^{2-}$-free conditions were assured by using $\mathrm{N}_{2}$ atmosphere during each preparation.

The XRD pattern of the solids precipitated from the solutions described above are presented in Fig. 1. The preparation of CaAl-LDHs was successful in both cases. When the mixed solution of the $\mathrm{Ca}^{2+} / \mathrm{Al}^{3+}$ metal ions was added to the $\mathrm{NaOH}$ solution, in addition to the peaks corresponding to the LDHs, the formation of a small amount of $\mathrm{Ca}(\mathrm{OH})_{2}$ can also be seen (see Fig. 1, at $18.0^{\circ} 2 \theta$ value). The distance between the layers calculated from the (003) peak $\left(11.23^{\circ} 2 \theta\right.$ value) was found to be $0.787 \mathrm{~nm}$ for each sample. For 


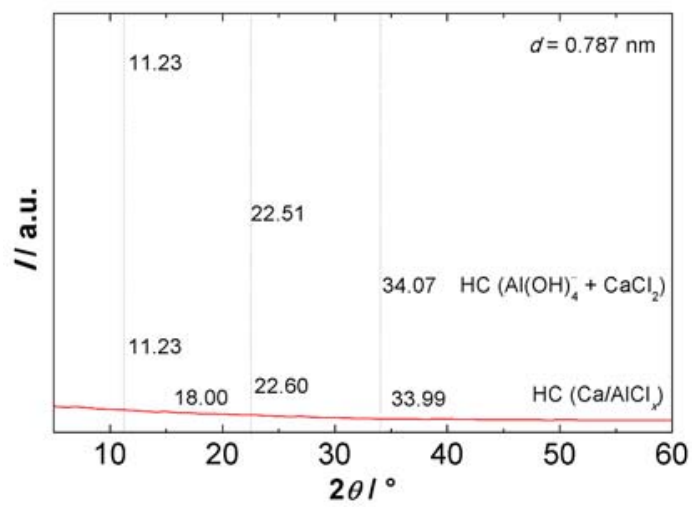

Fig. 1. Powder XRD diffraction pattern of two hydrocalumite samples (red: $\mathrm{NaOH}+\mathrm{CaCl}_{2} / \mathrm{AlCl}_{3}$; blue: $\left.\mathrm{Al}(\mathrm{OH})_{4}^{-} / \mathrm{NaOH}+\mathrm{CaCl}_{2}\right)$.

the CaAl-LDH sample prepared from $\mathrm{Al}(\mathrm{OH})_{4}^{-}$, the more intense peaks and smaller FWHM values indicate a significantly larger crystal size (Note that the integral of the respective diffraction peaks for both samples remained almost equal.).

With the addition of $\mathrm{Ca}^{2+}$ to the solution containing $\mathrm{Al}(\mathrm{OH})_{4}^{-}$and $\mathrm{NaOH}, \mathrm{CaAl}-\mathrm{LDH}$ was formed containing virtually no by-product (e.g., $\mathrm{Ca}(\mathrm{OH})_{2}$, $\left.\mathrm{Al}(\mathrm{OH})_{3}\right)$. Hence, the effect of the drying and/or the carbonate ion is presented via this sample.

The SEM/SEM-EDX image of the CaAl-LDH precipitated from $\mathrm{Al}(\mathrm{OH})_{4}^{-} / \mathrm{NaOH}+\mathrm{CaCl}_{2}$ solution at a magnification of 15,000 is presented in Fig. 2. The images confirm the results derived from the XRD measurements. The uniform distribution (Fig. 2B) of the calcium and aluminium ions in the lamella-like particles (Fig. 2A) indicates that the white precipitate is not a mixture of calcium and aluminium hydroxide but an $\mathrm{LDH}$.

The way the LDHs were dried was systemati-

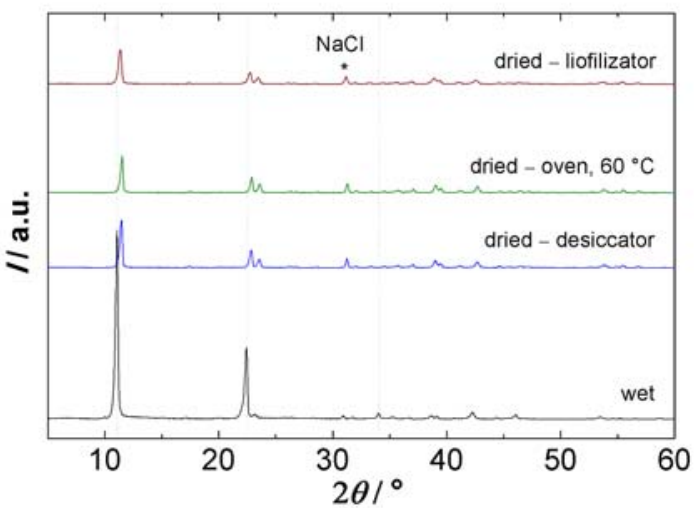

Fig. 3. Effect of drying method on powder XRD pattern of HC; prepared from $\mathrm{Al}(\mathrm{OH})_{4}^{-} / \mathrm{NaOH}+\mathrm{CaCl}_{2}$.

cally studied on the products obtained using both preparation methods. They were as follows: (i) drying over $\mathrm{P}_{2} \mathrm{O}_{5}$ in desiccators at ambient temperature; (ii), drying in an oven at $60^{\circ} \mathrm{C}$ with dry air, and (iii) freeze-drying (lyophilisation). The effect of the drying method on the XRD pattern of CaAl-LDH prepared using $\mathrm{CaCl}_{2}$, and the SEM pictures of these samples, are presented in Figs. 3 and 4, respectively.

With any type of drying, a small decrease in the interlayer distance can be observed (Fig. 3), since the 003 peak appears at $11.63^{\circ} 2 \theta$ value - an increase of $0.40^{\circ}$. This $0.03 \mathrm{~nm}$ decrease in the interlayer distance can be interpreted as the elimination of some water molecules from the interlayer region of the LDH. In addition to the variation described previously, the drying of the $\mathrm{LDH}$ (either over $\mathrm{P}_{2} \mathrm{O}_{5}$ in a desiccator, with dry air at $60^{\circ} \mathrm{C}$, or by freeze-drying), the crystal size of the CaAl-LDH decreased significantly. Thus, the solid, which precipitates from the aluminate solutions, is best represented by the wet crystals. No
A

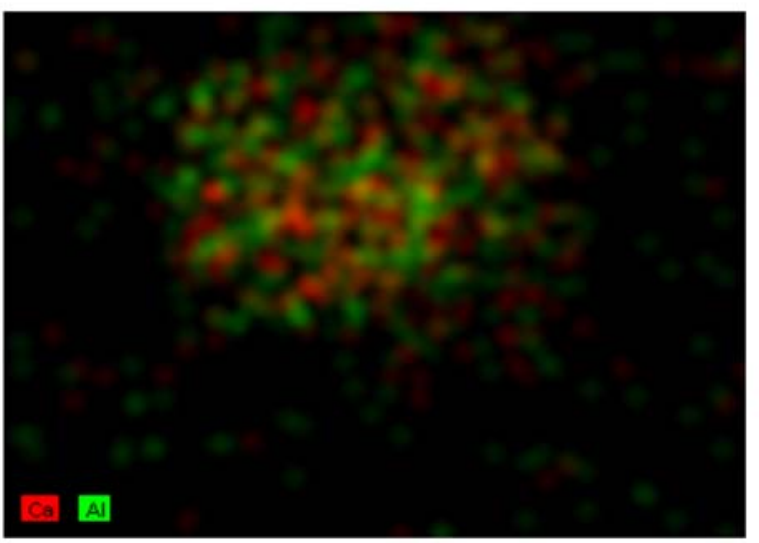

B

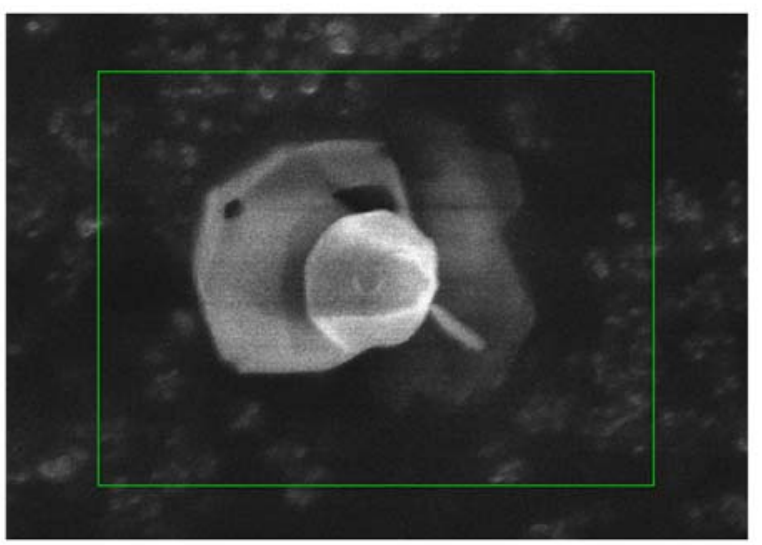

Fig. 2. SEM (A) and SEM-EDX (B) images of CaAl-LDH (15,000 magnification) precipitated from $\mathrm{Al}(\mathrm{OH})_{4}^{-} / \mathrm{NaOH}^{-} \mathrm{CaCl}{ }_{2}$ solution at $60^{\circ} \mathrm{C}$. 
A

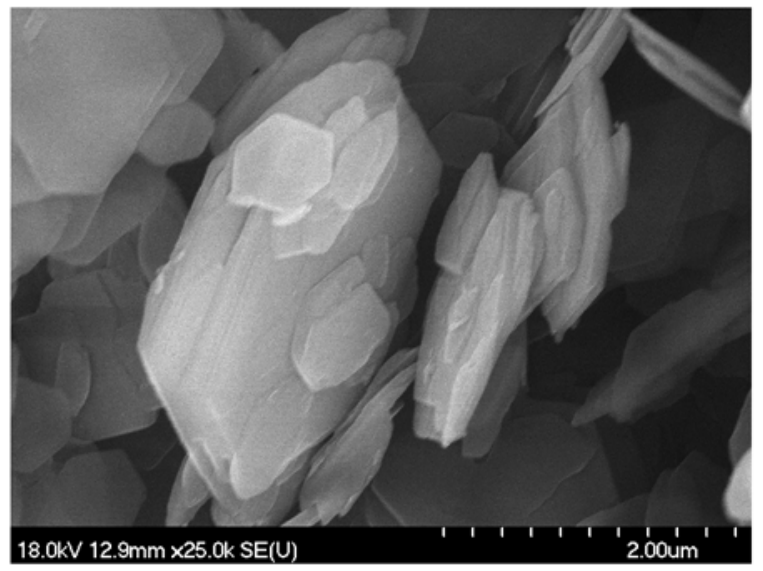

$\mathrm{C}$

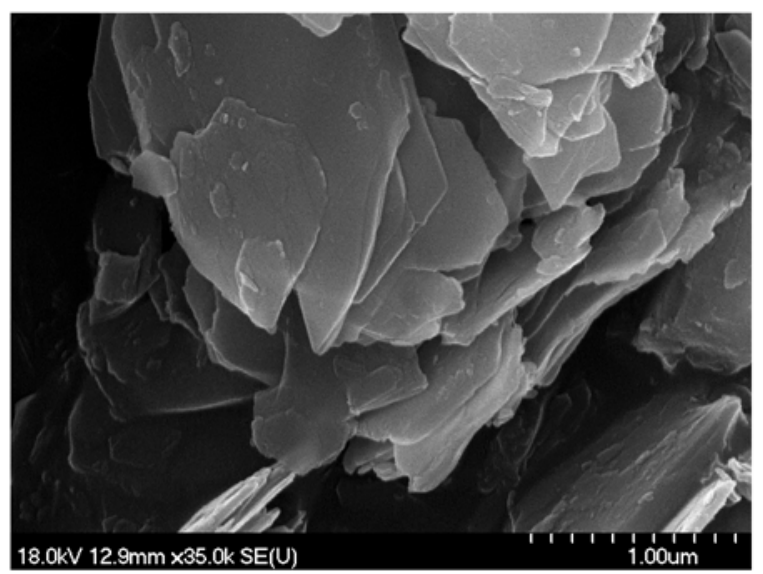

B

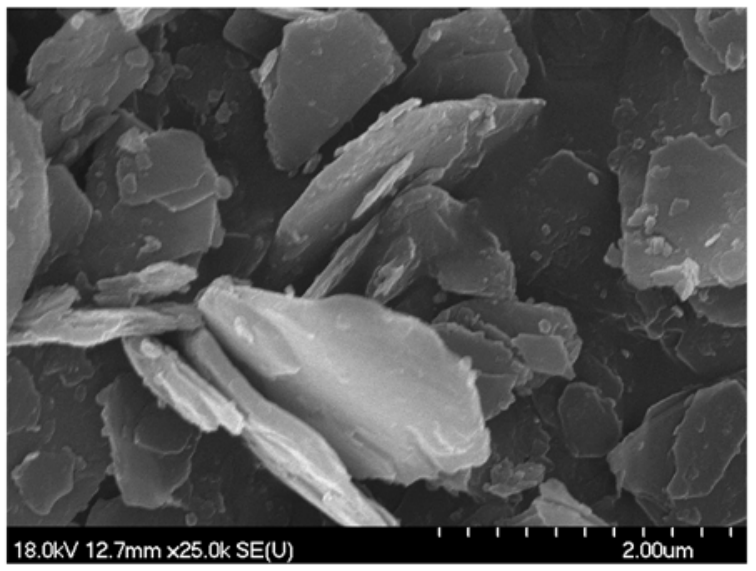

D

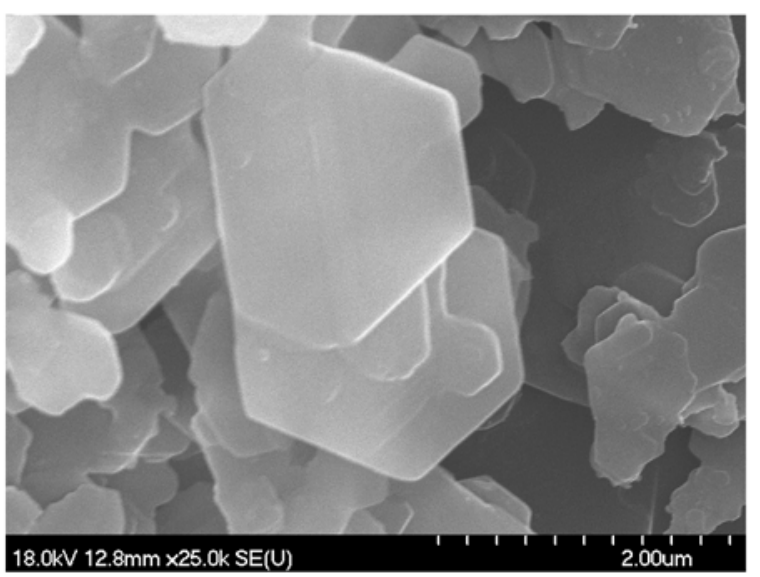

Fig. 4. SEM images of $\mathrm{HC}$ precipitated from $\mathrm{Al}(\mathrm{OH})_{4}^{-} / \mathrm{NaOH}+\mathrm{CaCl}_{2}$ solution at $60^{\circ} \mathrm{C}$ with different drying methods; wet $(\mathrm{A})$, dried in desiccator (B), dried in oven at $60^{\circ} \mathrm{C}(\mathrm{C})$, dried in freeze-dryer (D).

carbonate intercalation and/or contamination can be observed in the samples.

With regard to the technical use of the LDHs, the freeze-dried samples can be considered to be the most difficult or circuitous samples to handle. With the drying, a very loose and fine solid was formed. In the absence of the cohesion between the solid particles, sticking the sample to the sample-holder was found to be difficult. As far as the remaining three samples are concerned, no technical differences could be observed.

The effect of the carbonate ion is exhibited on the wet samples. The carbonate-containing CaAl-LDHs were prepared using the modified co-precipitation method detailed above. The $\mathrm{CaCl}_{2}$ solution was added slowly to the $\mathrm{Al}(\mathrm{OH})_{4}^{-}$- and $\mathrm{Na}_{2} \mathrm{CO}_{3}$-containing alkaline solution at $(60 \pm 1)^{\circ} \mathrm{C}$. Two different $\mathrm{CO}_{3}^{2-}$ concentrations were used during the synthesis, in order to form either the hemicarbonate or the monocarbonate form of the CaAl-LDH. In these forms, the $\mathrm{Al}^{3+}: \mathrm{CO}_{3}^{2-}$ ratio is $2: 1$ and $1: 1$, respectively. The white precipitates were stirred continuously overnight prior to filtration and $\mathrm{CO}_{3}^{2-}$-free conditions were maintained throughout each preparation

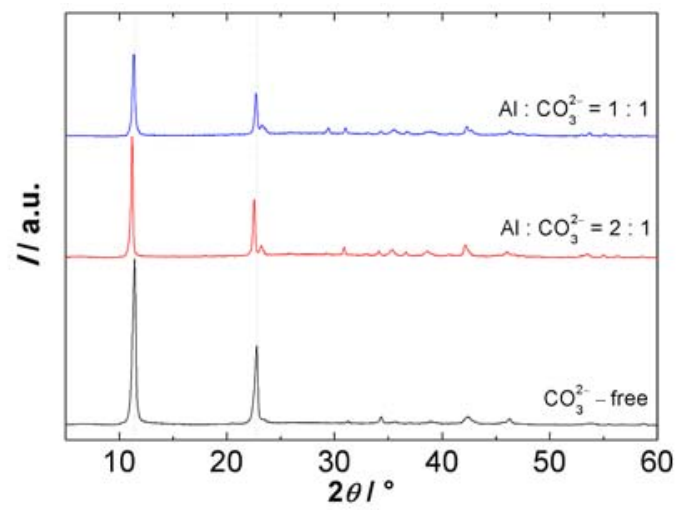

Fig. 5. Effect of carbonate ion on CaAl-LDH prepared as $\mathrm{Al}(\mathrm{OH})_{4}^{-} / \mathrm{NaOH}+\mathrm{CaCl}_{2}$ (wet samples).

and filtration to keep the $\mathrm{Al}^{3+}: \mathrm{CO}_{3}^{2-}$ ratio constant. The XRD patterns of the solids precipitated from the systems described above are presented in Fig. 5 .

$\mathrm{CO}_{3}^{2-}$-containing $\mathrm{CaAl}-\mathrm{LDH}$ s were successfully prepared in both cases. No sign of by-product formation (e.g., $\mathrm{CaCO}_{3}$ ) can be observed on the XRD 
pattern (Fig. 5); i.e., the presence of the $\mathrm{CO}_{3}^{2-}$ does not deter the formation of the $\mathrm{Ca}_{2} \mathrm{Al}-\mathrm{LDH}$. With the intercalation of the $\mathrm{CO}_{3}^{2-}$, a small increase in the interlayer distance can be observed, as the 003 peak appears at $\approx 0.20^{\circ}$ lower $2 \theta$ value. This is due to the minor difference in the size of the intercalated anion (carbonate vs hydroxide).

The presence of the $\mathrm{CO}_{3}^{2-}$ in the interlayer does not affect the morphology of the particles precipitated. The effects of the drying accord with those found for the $\mathrm{CO}_{3}^{2-}$-free samples. Apart from the minor decrease in the interlamellar distance, no other changes can be observed.

\section{Conclusions}

The preparation of $\mathrm{Ca}_{2} \mathrm{Al}-\mathrm{LDH}$ s with various carbonate contents was successful using both the coprecipitation method and its modified version. The addition of $\mathrm{Ca}^{2+}$ to an $\mathrm{Al}(\mathrm{OH})_{4}^{-}$yielded a more uniform product without the formation of by-products. The presence of the $\mathrm{CO}_{3}^{2-}$ ion in the liquid phase did not inhibit the formation of the $\mathrm{Ca}_{2} \mathrm{Al}-\mathrm{LDH}$. The method of drying had only a minor effect on the interlayer distance but it significantly affected the crystal size of the CaAl-LDH. Accordingly, the solid which precipitates from the aluminate solutions is best represented by the wet crystals. No carbonate intercalation and/or contamination was observed during the drying of the LDHs.

Acknowledgements. This research was financed by the $\mathrm{Na}$ tional Research Fund of Hungary through grant no. NK 106234 and the TAMOP 4.2.2.A-11/1/KONV-2012-0047 grant of the European Union and Hungary. V.T. and M.S. gratefully acknowledge the support of the TAMOP 4.2.4.A/2-11-1-20120001 National Excellence Programme.

\section{References}

Chrysochoou, M., \& Dermatas, D. (2006). Evaluation of ettringite and hydrocalumite formation for heavy metal immobilization: Literature review and experimental study. Journal of Hazardous Materials, 136, 20-33. DOI: 10.1016/j.jhazmat. 2005.11.008.
Hobbs, M., Zhang, M., \& Wang, Y. (2003). Competitive anion sorption in hydrocalumites. In Proceedings of the 2003 International Symposium on South-East Asian Water Environment, October 23-25, 2003 (pp. 204-208). Bangkok, Thailand: Press of the Asian Institute of Technology.

Messersmith, P. B., \& Stupp, S. I. (1992). Synthesis of nanocomposites: Organoceramics. Journal of Materials Research, 7, 2599-2611. DOI: 10.1557/jmr.1992.2599.

Palmer, S. J., Frost, R. L., \& Nguyen, T. (2009). Hydrotalcites and their role in coordination of anions in Bayer liquors: Anion binding in layered double hydroxides. Coordination Chemistry Reviews, 253, 250-267. DOI: 10.1016/j.ccr.2008.01.012.

Perrotta, A. J., \& Williams, F. (1995). Hydrocalumite formation in Bayer liquor and its promotional effect on oxalate precipitation. Light Metals, 1995, 77-87.

Perrotta, A. J., Williams, F. S., \& Stonehouse, L. (1997). Layered double hydroxides for treatment of Bayer process lake water. Light Metals, 1997, 37-48.

Rousselot, I., Taviot-Guého, C., Leroux, F., Léone, P., Palvadeau, P., \& Besse, J. P. (2002). Insights on the structural chemistry of hydrocalumite and hydrotalcite-like materials: Investigation of the series $\mathrm{Ca}_{2} \mathrm{M}^{3+}(\mathrm{OH})_{6} \mathrm{Cl} \cdot 2 \mathrm{H}_{2} \mathrm{O}$ $\left(\mathrm{M}^{3+}: \mathrm{Al}^{3+}, \mathrm{Ga}^{3+}, \mathrm{Fe}^{3+}\right.$ and $\left.\mathrm{Sc}^{3+}\right)$ by X-ray powder diffraction. Journal of Solid State Chemistry, 167, 137-144. DOI: 10.1006/jssc.2002.9635.

Sipos, P., Hefter, G., \& May, P. M. (1998). A hydrogen electrode study of concentrated alkaline aluminate solutions. Australian Journal of Chemistry, 51, 445-454. DOI: 10.1071/c97220.

Sipos, P., May, P. M., \& Hefter, G. T. (2000). Carbonate removal from concentrated hydroxide solutions. The Analyst, 125, 955-958. DOI: 10.1039/a910335j.

Williams, F. S., \& Perrotta, A. J. (1998). US Patent No. $5,728,180$. Washington, DC, USA: US Patent and Trademark Office.

Zhang, M., \& Reardon, E. J. (2005). Chromate and selenate hydrocalumite solid solutions and their applications in waste treatment. Science in China Series C: Life Sciences, 48(Supplement), 165-173.

Zümreoglu-Karan, B., \& Ay, A. N. (2012). Layered double hydroxides - multifunctional nanomaterials. Chemical Papers, 66, 1-10. DOI: 10.2478/s11696-011-0100-8. 